\title{
Single Phase Full Bridge Inverter Control as Reactive Power Compensator
}

\author{
Anang Budhi Nugroho ${ }^{1}$, Eka Firmansyah ${ }^{2}$, Suharyanto ${ }^{2}$
}

\begin{abstract}
The drop of local load voltage on the distribution system is an indicator that the system experiences reactive power shortage. It can be overcome by an inverter controlled to compensate reactive power. The benefit of the inverter is that it is easily configured with a variety of functions. This paper presents the control configuration of inverter as reactive power compensators. The method used is a current control system of the proportional integrator (PI) - dq based transformation. This method generates reactive power by regulating the current domain $\left(I_{d}\right.$, ref $\left.=0\right)$, while the current domain $\left(I_{q}\right.$, ref $)$ is set according to the need. Phase locked loop (PLL) is added so that the inverter can be synchronized well with the grid. According to the analysis of the PI current control, the local load voltage is stable at $219.88 \mathrm{~V}_{\text {rms }}$ and the reactive power generated by the inverter is 298 VAR with steady state error $0.11 \%$ of the reference power without oscillation.
\end{abstract}

Keywords--single-phase full bridge inverter, reactive power compensator, current control of proportional integrator, voltage drop.

\section{INTRODUCTION}

Inverter with a small capacity is known as a micro-inverter [1]. Micro-inverter has several advantages compared with central inverter and string inverter, for example: configurations of the inverter are easily developed for active and reactive power supply and avoiding fire on a rooftop while working as reactive power compensator. The control system is an important concern for maintaining the stability of the overall system.

Micro-inverter can be classified into two types, namely single and dual stage. Dual-stage micro-inverter is used to improve ripple and efficiency of the single stage technique. There are two stages of power conversion of dual-stage technique, the dc-dc converter, and dc-ac inverter. Conversion of dc to ac utilizes full bridge inverter [2]. The control of the dc-ac inverter is applied to integrate the inverter to the grid so that the local load simultaneously receives supply from the inverter and the grid. The algorithm of phase locked loop (PLL) is added in order to integrate the inverter to the grid.

Problems occur when the voltage drops across the local load. The voltage drop across the local load on the distribution system is an indicator that the reactive system experiences

\footnotetext{
${ }^{1}$ Graduate Student, Department of Electrical and Information Engineering, Faculty of Engineering, Universitas Gadjah Mada, Jl. Grafika 2 Yogyakarta 55281 INDONESIA (tlp/fax: 0274-547506, 0274-510983; e-mail: anangbudhi.sie14@mail.ugm.ac.id)

${ }^{2}$ Lecturer, Department of Electrical and Information Engineering, Faculty of Engineering, Universitas Gadjah Mada, Jl. Grafika 2 Yogyakarta 55281 INDONESIA(tlp/fax: 0274-547506, 510983; e-mail: eka.firmansyah@gmail.com, suharyanto@ugm.ac.id)
}

power shortage caused by impedance network at a certain distance and resistive-inductive local load. The purpose of this paper is that the inverter is controlled only to compensate reactive power in the local load and active power supplied by the grid, in the system of the dual stage micro-inverter.

The current control method of the proportional integrator (PI) - dq based transformation is proposed to overcome it. Dq transformation requires two input signals in the form of $\alpha \beta$ and reference angle. Reference angle of $\theta_{\text {ref }}$ transformation of dq algorithm is obtained by PLL. PI current control block is used to control the steady-state error at the output inverter. Power control system of the inverter is analyzed using power simulator software (PSIM).

\section{INVERTER OPERATION AGAINST GRID AND LOAD}

Inverter can be configured with a variety of functions. The development of the inverter is to improve the quality of power supply voltage. The power of the inverter is 300 watts. In this voltage, the inverter works independently without being integrated into the grid, therefore if there is a shortage or power excess, the inverter cannot send or absorb the power from the grid. The inverters are installed in series with a resistive load, so that they do not take into account the voltage drop across the resistive-inductive load. SPWM pulse generator technique based on direct digital synthesis (DDS) is the implementation of previous studies discussing the inverter to repair electric voltage quality in dense urban households [3].

A wide application of the micro-inverter is to integrate it with the grid. The main purpose of the integration is to maintain the supply of electricity distribution to work well. The power supplied by the inverter to the grid is influenced by the load angle $\delta$ between the inverter and the grid and the magnitude of output inverter. The output inverter is maintained, while the frequency, phase, and magnitude inverter can be controlled so that it can absorb or supply power when the inverter has shortage or power excess.

The inverter is only used to supply local load. Equations of power flow flowing at the point of common coupling (PCC) are presented in (1) and (2) [4].

$$
\begin{aligned}
& \mathrm{Q}_{\text {Load }}=\mathrm{Q}_{\text {inv }}+\mathrm{Q}_{\text {grid }} \\
& \mathrm{P}_{\text {load }}-\mathrm{P}_{\text {grid }}=0 .
\end{aligned}
$$

As shown in (1), the reactive power load is supplied by the inverter and the grid, whereas in (2), it is indicated that the active power load is fully supplied by the grid. This is due to the inverter does not operate in the condition of unity power factor. The relationship of power flow at the PCC is shown in Fig. 1. 


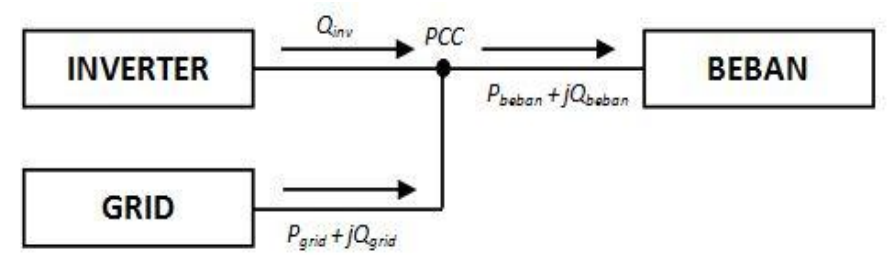

Fig. 1 Flow of inverter power and grid to the load.

\section{Single PhASE FUll BRIDGE INVERTER CiRCUIT}

The advantage of several configurations of the inverter is that the phase, magnitude, and frequency of the output inverter can be controlled [5]. The inverter uses topology of the full bridge which has the advantage of a simple design, but it generates output power twice higher than the topology of halfbridge [6]. Inverter full bridge is composed of four semiconductor switches, namely S1, S2, S3, and S4. Each switch is not allowed to operate simultaneously, as it may lead to short circuit at the source of dc [6], [7]. The topology of the full bridge inverter of the system of dual stage micro-inverter is shown in Fig. 2.

Specifications of the single-phase full bridge inverter as a compensator of reactive power are shown in Table I. Based on these parameters, it is obtained the single-phase full bridge inverter as reactive power compensator 300 VAR.

Mechanical switch of the inverter uses unipolar Sinusoidal Pulse Width Modulation (SPWM). The advantages of the unipolar SPWM is that it has a lower harmonic content than bipolar SPWM. Unipolar SPWM is formed from two different references of signals $180^{\circ}$ and triangle signal [8], [9].

The voltage of output rms inverter can be calculated using (3) [6], [10].

$$
\mathrm{V}_{\text {inv }}=\mathrm{ma} \times \mathrm{V}_{\mathrm{dc}} /(\sqrt{2})
$$

TABLE I

INVERTER SPECIFICATIONS

\begin{tabular}{|c|l|l|}
\hline No. & \multicolumn{1}{|c|}{ Parameter } & \multicolumn{1}{c|}{ Specification } \\
\hline 1 & $\mathrm{~V}_{\text {in }}$ the inverter & $500 \mathrm{~V}_{\mathrm{dc}}$ \\
\hline 2 & $\mathrm{~V}_{\text {out }}$ inverter & $318 \mathrm{~V}_{\mathrm{rms}}$ \\
\hline 3 & $\mathrm{I}_{\text {out }}$ inverter & $1.4 \mathrm{~A}_{\mathrm{rms}}$ \\
\hline 4 & Q inverter & $300 \mathrm{VAR}$ \\
\hline 5 & Freq. switching & $25000 \mathrm{~Hz}$ \\
\hline 6 & PWM Control & Unipolar SPWM \\
\hline 7 & Duty cycle & $50 \%$ \\
\hline 8 & Lcouple & $126 \mathrm{mH}$ \\
\hline 9 & Freq. grid & $50 \mathrm{~Hz}$ \\
\hline 10 & Load angle $\delta$ & $10^{0}$ \\
\hline 11 & Topology & Full bridge \\
\hline 12 & MOSFET & SCT30N120 \\
\hline
\end{tabular}

IV. TRANSFORMATION OF DQ

Voltage and current of output inverter full bridge are in the forms of sinusoidal ac. Sinusoidal output inverter can be controlled either by phase, magnitude, and frequency [5]. Constraints occur when the sinusoidal output inverter will be used as a feedback control in the system of the inverter full bridge because it is difficult to control the magnitude of the form of sinusoidal.

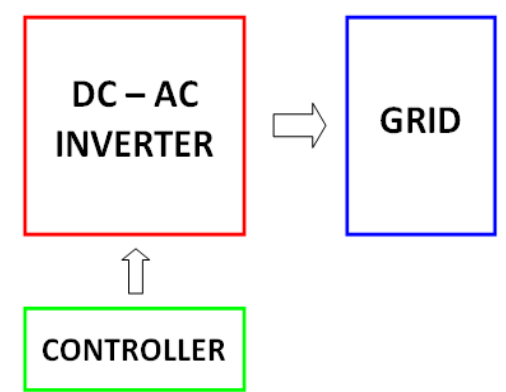

(a)

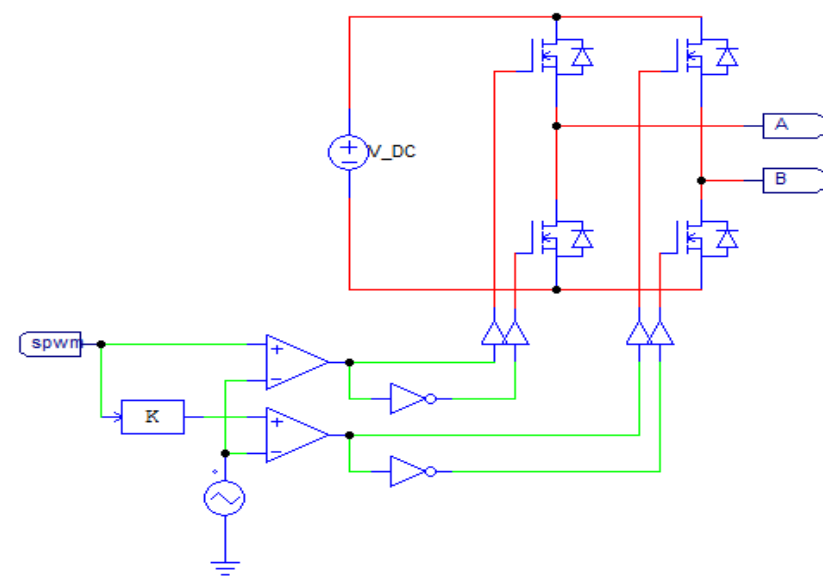

(b)

Fig. 2 Schematic system dual stage micro-inverter dc-section; an inverter (a) A block diagram of an inverter connected to the grid,(b) Inverter full bridge dc-ac with unipolar SPWM.

To facilitate the control system, the voltage in the rotating frame (amplitude voltages and current change following time will be in the form of sinusoidal) is transformed into the form of domain dq, but the single phase voltage cannot be directly transformed into a domain form dq so that it needs to be a two-phase prior to be domain $\alpha \beta$. Transformation of dq can map the magnitude of the ac in form of dc so that making it easier to control the system in stationary of dq.

Signal value $\alpha$ is equal to the value of the signal grid, while the value of signal $\beta$ is the result of a shift by $90^{\circ}$. Method of transport delay $T / 4$ is used to form a signal $\beta$ [11]. The signal in the form $\alpha \beta$ is then it is transformed to the frame dq. Transformation of $\mathrm{dq}$ requires a reference angle in transforming the signal $\alpha \beta$. The reference angle of $\theta_{\text {ref }}$ is obtained by the algorithms PLL [10]--[13]. PLL scheme is shown in Fig. 3.

Transformation of $\mathrm{dq}$ is implemented in the PI current control, forming the current signal $I_{d}$ and the current $I q$, and forming a voltage signal $V_{d}$ and $V_{q}$ in the circuit of power inverter counters.

The current magnitude within the framework of dq of the transformation of dq is shown in (4).

$$
\left[\begin{array}{l}
I_{d} \\
I_{q}
\end{array}\right]=I\left[\begin{array}{c}
\sin \left(\varphi_{i n}-\varphi_{r e f}\right) \\
-\cos \left(\varphi_{i n}-\varphi_{r e f}\right)
\end{array}\right]
$$

Transformation of dq is performed also on the amount of voltage. The result of the transformation is shown in (5). 


$$
\left[\begin{array}{c}
V_{d} \\
V_{q}
\end{array}\right]=V\left[\begin{array}{c}
\sin \left(\varphi_{\text {in }}-\varphi_{\text {out }}\right) \\
-\cos \left(\varphi_{\text {in }}-\varphi_{\text {out }}\right)
\end{array}\right]
$$

The angle $\theta$ in is the input phase angle, while $\theta$ out is the phase reference angle.

If $\theta$ in is taken from the angle $\alpha$, then $d$ will be zero, while $q$ will be -A. However, if $\theta$ in is taken from angles $\beta$, then $d$ will be A, while $q$ will be zero.

\section{Phase Locked LoOP (PLL)}

PLL is a system of closed loop that acts to integrate the inverter to the grid and to provide a reference angle on the transformation of dq. In real applications, the value of $\omega t$ changes in accordance with the load, so that the PLL is used for tracking changes in the phase angle. There are three main parts of the PLL, the phase detector (PD), a loop filter (LF), and a voltage controlled oscillator (VCO) [11], [13].

The working principle of the PLL is the PLL requires input of signal $\alpha \beta$ as an input to block the PD. The value $A$ is equal to the grid and the value of $\beta$ is a shift from the grid by $90^{\circ}$ The shift to form signal $\alpha \beta$ uses the transport delay $T / 4$ [11]. The magnitude of the grid in the domain $\alpha \beta$ is then transformed into the frame dq. When $\varphi_{\text {in }}$ is taken from the angle $\alpha$, then $V_{d}$ will be zero, while the $V_{q}$ will be $-\mathrm{V}$. However, if $\varphi_{\text {in }}$ is taken from the point $\beta$, then $V_{d}$ is $\mathrm{V}$, while $V_{a}$ is zero. When there is a difference between the angle $\varphi_{\text {ins }}$ and oouts, then an error is controlled at the LF. To obtain the grid voltage in domain dq, (6) is used.

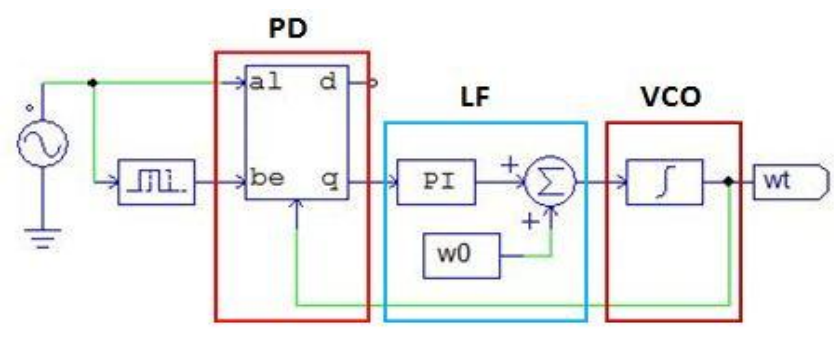

Fig. 3 Scheme of phase locked loop.

$$
\left[\begin{array}{l}
V_{d} \\
V_{q}
\end{array}\right]=V\left[\begin{array}{c}
\sin \left(\varphi_{\text {in }}-\varphi_{\text {out }}\right) \\
-\cos \left(\varphi_{\text {in }}-\varphi_{\text {out }}\right)
\end{array}\right]
$$

Section of LF is part of PI control to compensate for the input phase angle to output phase angle. VCO is obtained from the calculation error obtained from PI control added to the reference angle $\omega_{0}$ set $2 \pi f_{0}$, with frequency $f_{0}=50 \mathrm{~Hz}$. The calculation results are to be integral so that the value of angle output $\theta_{\text {out }}$ becomes equal to the input angle $\theta$ in. The PLL circuit schematic is shown in Fig. 3.

\section{CONTROL Operation INVERTER}

A schematic block diagram of inverter control operation is shown in Fig. 4. The inverter is controlled using current control with current detection feedback to output inverter and the current reference. Control of inverter is done by PI current control based on transformation of dq. Transformation of dq can map the magnitude of the ac in form of dc that makes it easier to control the system in stationary of dq [11], [13].

Power calculation in the frame of $\mathrm{dq}$ can be calculated using (7) and (8).

$$
\begin{aligned}
& P=\frac{1}{2}\left(V_{d} \cdot I_{d}+V_{q} \cdot I_{q}\right) \\
& Q=\frac{1}{2}\left(V_{d} \cdot I_{d}-V_{q} \cdot I_{q}\right)
\end{aligned}
$$
(10).

The calculation is indicated by the current reference (9) and

$$
\begin{aligned}
& I_{d, r e f}=\frac{2\left(V_{q} \cdot Q_{r e f}+V_{d \cdot} \cdot P_{r e f}\right)}{V_{d}{ }^{2}+V_{q}{ }^{2}} \\
& I_{q, r e f}=\frac{2\left(V_{q} \cdot Q_{r e f}-V_{d} \cdot P_{r e f}\right)}{V_{d}{ }^{2}+V_{q}{ }^{2}}
\end{aligned}
$$

Current reference is set-point used in the PI control. Feedback from the current of the output inverter is transformed into dq frame. The error between the current of the output inverter and a reference current is then compensated and controlled in the control block of PI current.

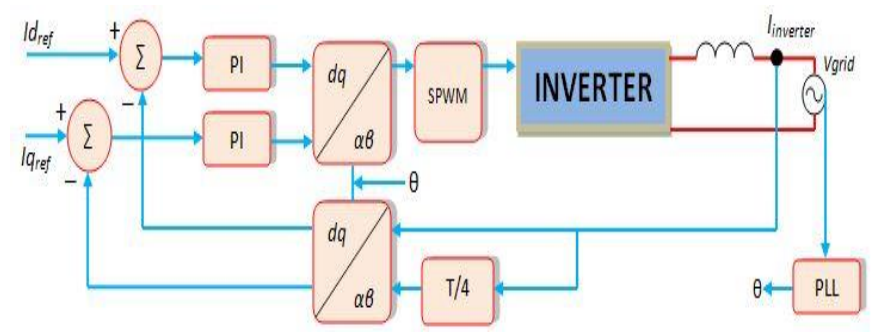

Fig. 4 Scheme of reactive power control operation.

In terms of the control system, switch of MOSFET in the inverter circuit is controlled by the unipolar signal of SPWM generated in control of the inverter block. The inverter is controlled by a PI-based current control transformation of dq through current detection of the feedback output inverter on the inductor coupling (Lcouple). The feedback current is then transformed into the domain shape current $I_{d}$ and $I_{q}$ with dq transformation. The dq transformation requires two inputs of $\alpha \beta$ that the difference is $90^{\circ}$ and reference angle in the transformation process. Transport delay $T / 4$ is used to form a signal, $\beta$ while the reference angle is obtained from PLL algorithms. The dq transformation can map magnitude of ac in the form of massive of dc, making it easier to control the system in stationary dq. Then, after it is obtained in the domain of the current $I_{d}$ and $I q$, domain currents $\left(I_{d}, I q\right)$ are included in the calculation by comparing with reference current inverter form ( $I_{\text {Dref }}$,Iqref). Reference of current ( $I_{\text {dref }}$, Iqref) is the set-point for the control PI and it is raised manually. Then, after calculating the current of both components and if there are errors in both, then the errors will be controlled and compensated at the current PI control block to maintain the output inverter to remain stable at the current 
of 1.36 A. Generation of reactive power at the inverter is done by determining $P_{\text {ref }}=0$ watt and $Q_{\text {ref }}$ as desired, or by way of setting $I_{d r e f}=0$, while $I_{\text {qref }}$ is set as desired. By way of determination of the reference value $\left(P_{\text {ref }}, Q r e f\right)$, it is obtained reactive power generated by the inverter. PLL is a system closed loop that is used for synchronization so that the output generated by the inverter is maintained to be similar to the grid. Another function of PLL is to provide a reference angle for the transformation of dq.

Simply, to make the inverter operates is only by generating reactive power that is by managing $P_{r e f}=0$ watt, while $Q_{r e f}$ is set at $300 \mathrm{VAR}$ or by regulating the current domain $I_{\text {Dref }}=0$, while the current domain $I_{\text {qref }}$ is set according to need.

\section{NETWORK MODELING}

In an integrated system with the grid, it is necessary to consider the voltage drop across the load point to be an important concern. Variations of the voltage at load point by the standards of PLN are namely between 198 volts 231 volts. For a single-phase system with $\cos \varphi \approx 1$, the calculation of voltage drop across the load point shown in Fig. 5 . Distance service low-voltage distribution from the source to the load is 300 meters [14]. Selection and modeling of the conductor cross-sectional area are calculated by (11).

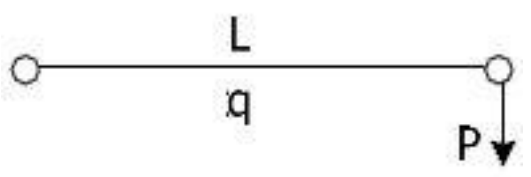

Fig. 5 Drop of the voltage at the point of load.

$$
\mathrm{q}=\frac{(2 \mathrm{~L} \times \mathrm{P} \times 100)}{\mathrm{V}^{2} \times \Delta \mathrm{u} \times \sigma}
$$

If the voltage drops $5 \%$, load of the inverter is 300 watts, 220 volt on a conductor of aluminum at a distance of 300 meters, thus:

$$
\begin{gathered}
\mathrm{q}=\frac{(2 \mathrm{~L} \times \mathrm{P} \times 100)}{\mathrm{V}^{2} \times \Delta \mathrm{u} \times \sigma} \\
\mathrm{q}=\frac{(2 \times 300 \times 300 \times 100)}{220^{2} \times 5 \times 32.7} \\
=2.27 \mathrm{~mm}^{2} .
\end{gathered}
$$

Therefore, the voltage of conductor drops at least 5\% having the size of a conductor of $2.5 \mathrm{~mm}^{2}$ In this study, the size of the conductor refers to the low voltage network system design of PLN, with the size of the conductor of $35 \mathrm{~mm}^{2}$.

The low voltage network impedance modeling carried out by the resistance and inductance are linked in series on the network. Network impedance affects the capacity of distributed power and influence on the occurrence of a voltage drop at the end of the line. Rated impedance in this study is modeled and refers to low voltage distribution systems of PLN with the type of conductor of NFA2X-T with kinds all aluminum alloy conductor (AAAC) with a conductor cross- sectional area of $35 \mathrm{~mm}^{2}$, which has a value resistance of $0.958 \Omega / \mathrm{Km}$ and reactance value of $0.378 \Omega / \mathrm{Km}$ [15], [16].

The impedance at the point of load is modeled with a full load condition on the output inverter $300 \mathrm{VAR}$ with $\cos \varphi \approx$ 0.71 , therefore, it is obtained the value of the parameters as follows:

resistance value

$$
R=V^{2} / P=220^{2} / 300=161.4 \Omega
$$

apparent power (13)

$$
S=P / \operatorname{Cos} \varphi=300 / 0.71=422.5 V A
$$

reactive power (14)

$$
Q=\sqrt{S^{2}}-P^{2}=\sqrt{422.5^{2}}-300^{2}=296 V A R
$$

inductance value $\cos \varphi=0.71$

$$
\begin{aligned}
& X_{L}=V^{2} / Q=220^{2} / 296=163.51 \Omega . \\
& L=X_{L} / 2 \pi f=163.51 / 314=0.520 \mathrm{H} .
\end{aligned}
$$

in order to obtain the value of the impedance of the full load.

$$
Z=R+j X=161.4+j 163.51 \Omega . .
$$

Due to the installation of a resistive-inductive load, it is connected in parallel with the source, the impedance is converted into a series circuit.

$$
\begin{aligned}
Z_{S} & =(\mathrm{R} \times \mathrm{X}) /(\mathrm{R}+\mathrm{X}) \\
& =(161.4 \times \mathrm{j} 163.51) /(161.4+163.51) \\
& =81.74+j 80.69 \Omega .
\end{aligned}
$$

to obtain the value of the resistance of the series load of 81.74 $\Omega$ and the value of the reactance of the series load is $80.69 \Omega$. Reactance value is changed to get the value of the load inductance of $256 \mathrm{mH}$.

Rated impedance of conductors consists of resistance of $0958 \Omega / \mathrm{Km}$ and reactance value of $0.378 \Omega / \mathrm{Km}$. Reactance value can be converted into a conductive wire inductance value through the following calculation.

$$
L=X_{L} / 2 \pi f=0.378 / 314=0.0012 \mathrm{mH} .
$$

It is obtained by the network inductance value of 0.0012 $\mathrm{mH} / \mathrm{km}$. Resistance-reactance value that is equivalent to load on the wire with network length of 300 meters is obtained by subtracting the full load of network impedance.

$$
\begin{aligned}
& R_{\text {Sal }}=300 \times 0.958 / 1000=0.29 \Omega \\
& L_{S a l}=300 \times 0.0012 / 1000=0.00036 \mathrm{mH} \\
& X_{L}=2 \pi f L=314 \times\left(3.6 \times 10^{-4}\right)=j 0.113 \Omega . .
\end{aligned}
$$

Thus, it is obtained $\mathrm{Z}_{\mathrm{s}}$ load

$$
\begin{aligned}
Z_{S} \text { load }= & (81.74+j 80.69)-(0.29+j 0.113) \\
= & 81.45+j 80.577 \Omega .
\end{aligned}
$$

Voltage drop measurement is done by using a resistiveinductive load of network distance 300 meters. The 
measurement results show that there is a significant voltage drop in the value of $\cos \varphi$ that becomes smaller. The results of measurements of the resistive-inductive loads are shown in Table II.

TABLE II

VOLTAGE DROP

\begin{tabular}{|c|c|c|c|c|}
\hline \multirow{2}{*}{$\begin{array}{c}\text { Cos } \\
\varphi\end{array}$} & \multicolumn{2}{|c|}{ Impedance } & \multirow{2}{*}{$\begin{array}{l}\text { Voltage } \\
\text { Load } \\
\text { (V) }\end{array}$} & \multirow{2}{*}{$\begin{array}{l}\text { Load } R(\Omega)+L \\
\quad(\mathrm{mH})\end{array}$} \\
\hline & $R(\Omega)$ & $L(\mathrm{mH})$ & & \\
\hline 0.71 & 0.29 & 0.00036 & 297.4 & $81.45+256$ \\
\hline 0.8 & 0.29 & 0.00036 & 298.7 & $103.34+245$ \\
\hline 0.85 & 0.29 & 0.00036 & 299.2 & $116.22+229$ \\
\hline 0.9 & 0.29 & 0.00036 & 304.8 & $129.74+202$ \\
\hline 0.95 & 0.29 & 0.00036 & 306.6 & $146.76+144$ \\
\hline
\end{tabular}

\section{RESULTS AND DISCUSSION}

In this paper, a simulation of the single phase inverter control as reactive power compensators with full bridge topology has been done using power simulator software (PSIM). Test and observation were conducted to investigate the results of reactive power generated by inverter to compensate the local load, PLL test, and the PI control test.

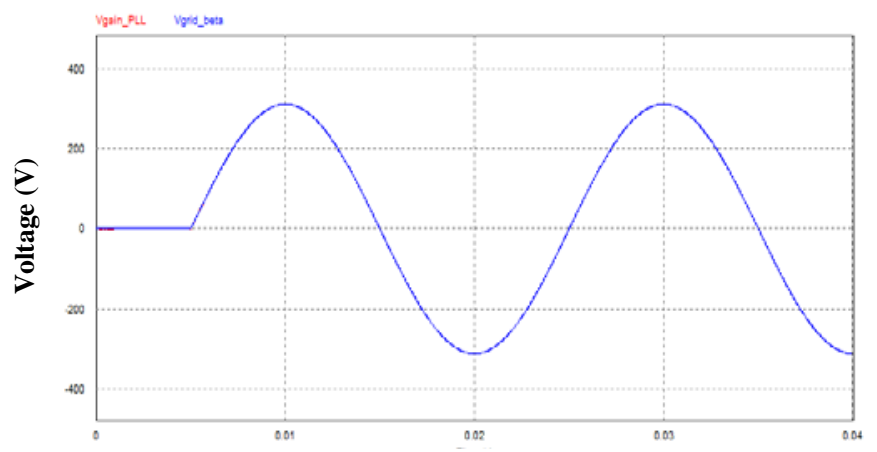

Time (s)

(a)

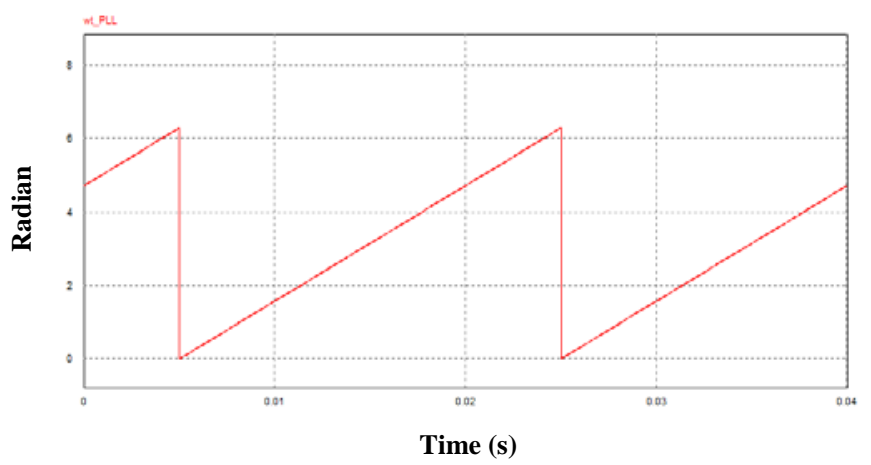

(b)

Fig. 6 PLL with a reference angle $\beta$, (a) the results of the synchronization inverter (blue signal) with the grid (red signal), (b) reference angle of PLL.

\section{A. Performance Results of Phase Locked Loop (PLL)}

From the simulation results and in accordance with Part IV, the signal $\beta$ is shifted by $90^{\circ}$. This shift is intended to form the signal $\beta$. PLL can synchronize grid voltage well at $\mathrm{t} \leq 0.005$ seconds. PLL transient time is affected by algorithm transport delay $T / 4$. Signal $\Omega t$ is generated by PLL with two wave periods and the result is equal to two periods of the grid signal, thus $\omega t$ can be used as a reference of angle for $\mathrm{dq}$ transformation applications. The test results of the PLL are shown in Fig. 6.

\section{B. Full Bridge Inverter System Performance Results}

Results of test to get a different angle $\delta$ are presented in Fig. 7. From the simulation, it can be seen that the determination of the reactance, therefore it is obtained angle $\delta$ of voltage inverter by $10^{0}$. The shift of the voltage inverter angle is displayed on one wave period when $t \geq 0.02$ seconds. It means that the current inverter can flow if there is a difference of angle $\delta$ between the inverter voltage and a voltage of the grid. Reactance serves to maintain current and load angle $\delta$.

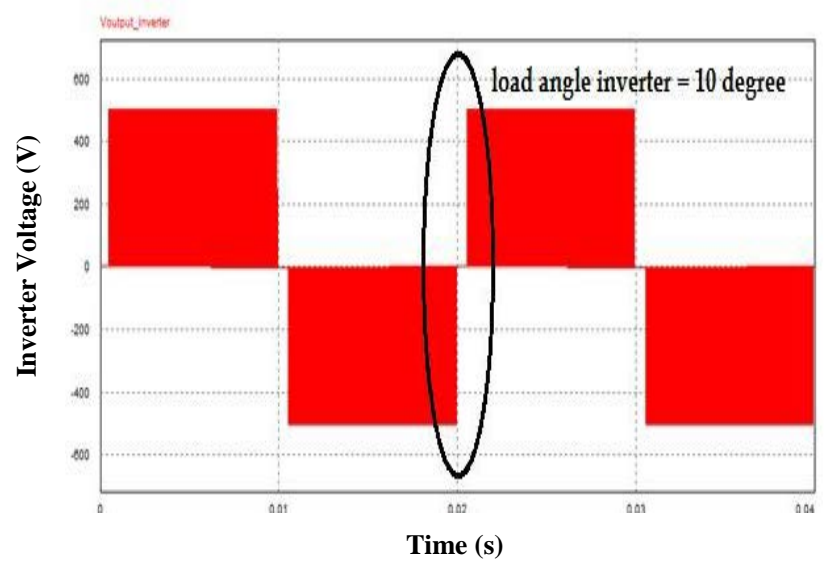

Fig. 7 Different angle $\delta$ inverter voltage.
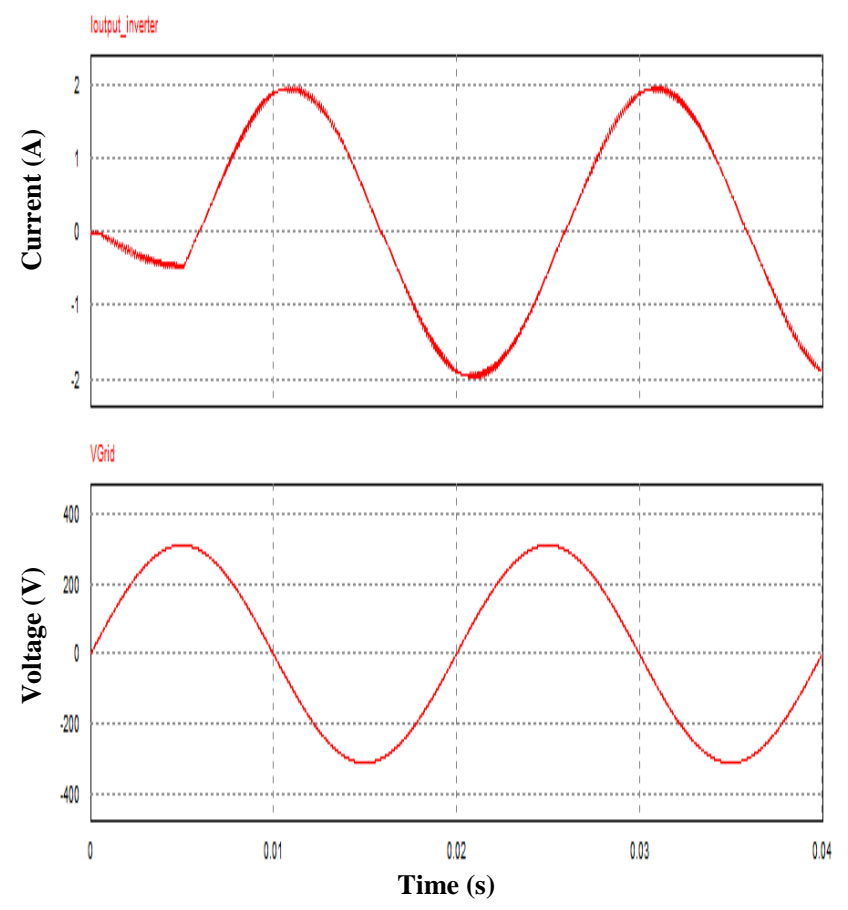

Fig. 8 The test results in current of inverter leading $90^{\circ}$ to the voltage grid. 


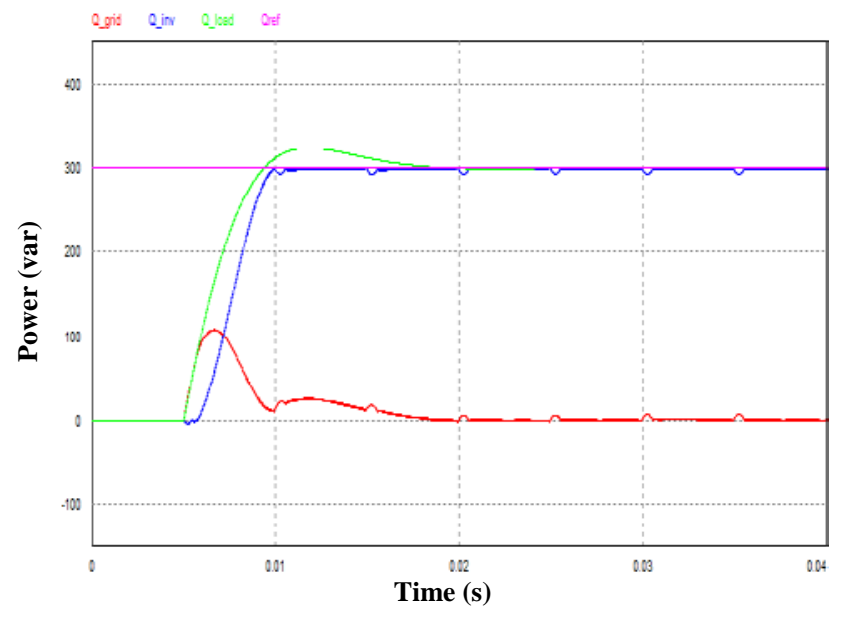

Fig. 9 Reactive power generated by inverter is 300 VAR.

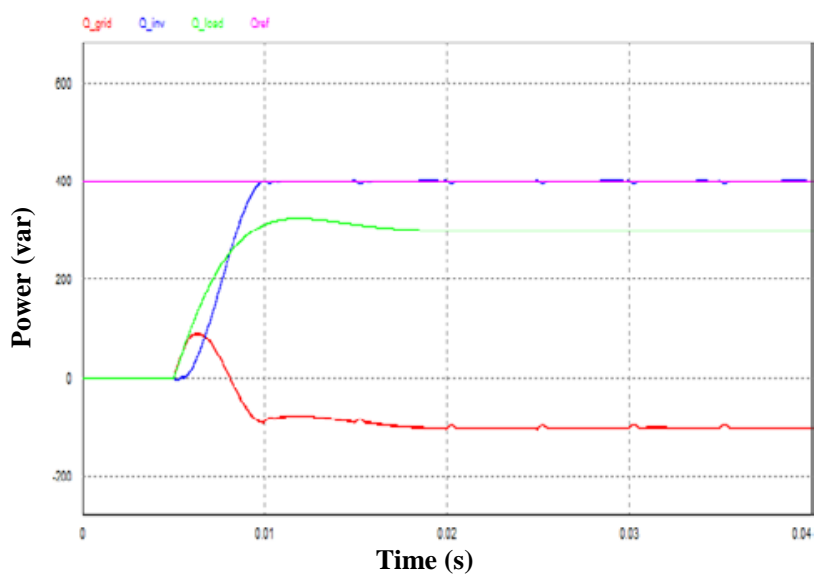

Fig. 10 Results of load distribution of 300 VAR, inverter power excess and the grid absorbs the inverter power excess.

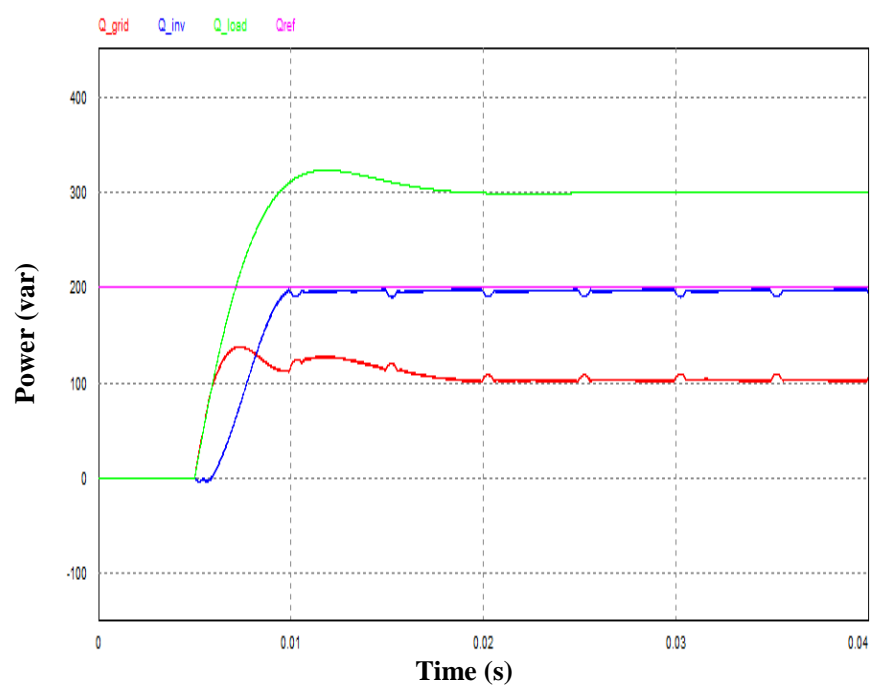

Fig. 11 Results of load distribution of 300 VAR, inverter experiences reactive power shortage and the grid absorbs inverter power excess.

From the test results and observation presented in Fig. 8, it appears that the current output inverter is leading $90^{\circ}$ to the grid voltage, which is obtained from the reference angle $\beta$ in the control of $\mathrm{dq}$ transformation. It means the inverter only sends reactive power

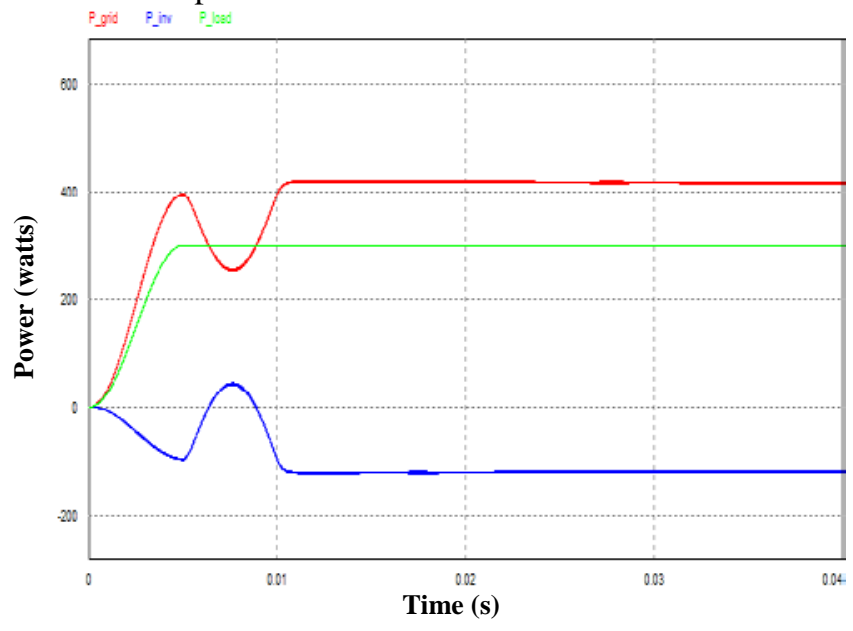

Fig. 12 Test on distribution of inverter active power and grid on load.

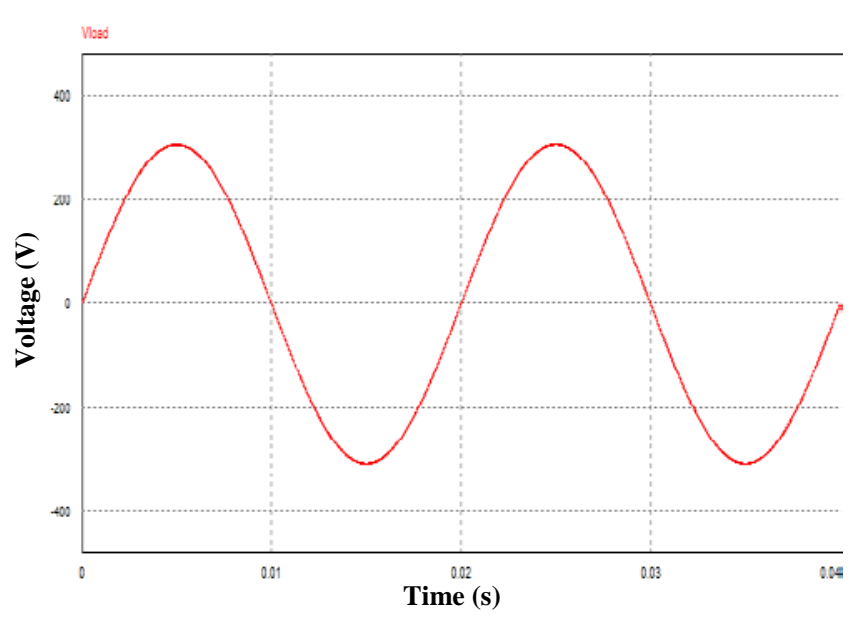

(a)

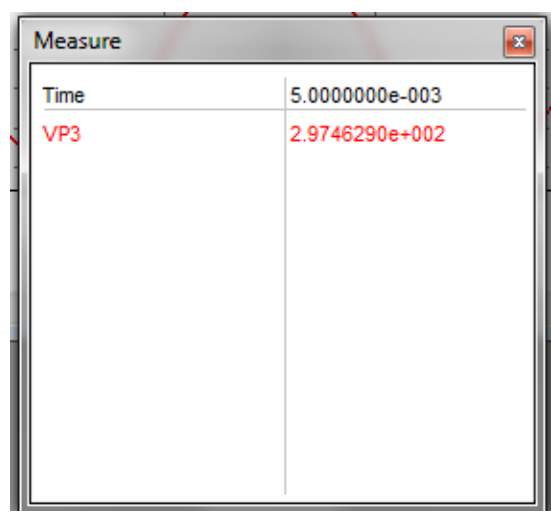

(b)

Fig. 13 The voltage at the load drops to $297 \mathrm{~V}_{\text {peak }}$, it should be $311 \mathrm{~V}_{\text {peak }}$ (a) Graph of voltage as a function of time, (b) Trace value at the peak point of the voltage wave.

From Fig. 7, Fig. 8, and specifications of the inverter presented in Table I, it appears that in these conditions, the inverter starts to generate reactive power required by the local load. 


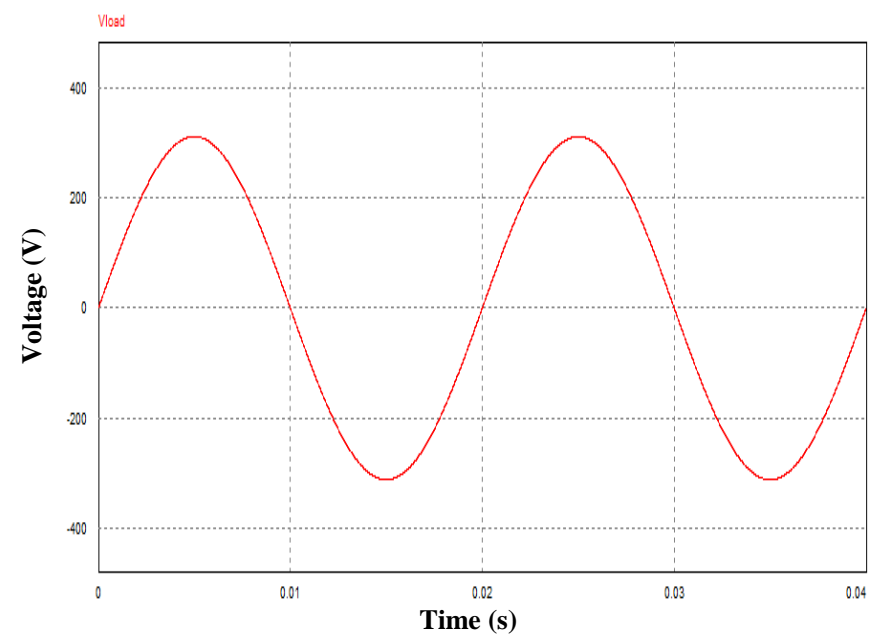

(a)

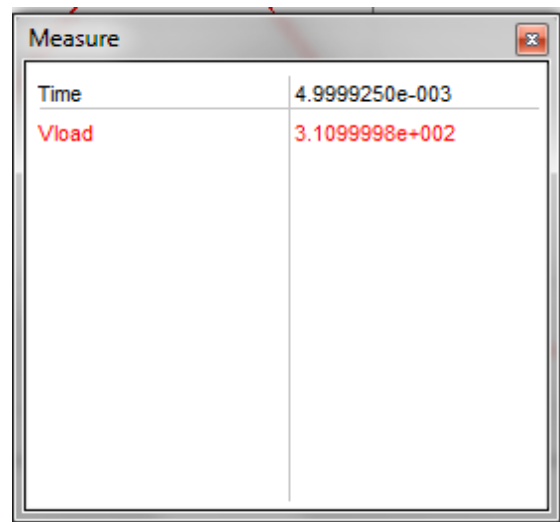

(b)

Fig. 14 The voltage at the load rises to $310999 \mathrm{~V}_{\text {peak }}$ (a) Graph of voltage as a function of time, (b) Trace value at the peak of the voltage wave.

Fig. 9 shows a load of 300 VAR (green signal) and the inverter generates reactive power of 300 VAR (blue signal). In this condition, the grid (red signal) does not supply or absorb shortage and excess of reactive power, as with a load of 300 VAR and the inverter generates reactive power of $300 \mathrm{VAR}$, thus the grid does not supply or absorb reactive power of the inverter.

As shown in Fig. 10, the inverter output generates 400 VAR reactive power (blue signal) and to supply a resistiveinductive load of 300 VAR (green signal), there is power inverter excess of $100 \mathrm{VAR}$ (red signal). Power inverter excess of 100 VAR is delivered to the grid.

It can be seen from the test results with the value of the reactive power load is $300 \mathrm{VAR}$, the reactive power inverter is 200 VAR, and the reactive power grid is 100 VAR. The test results and observation indicate that when the inverter generates reactive power that is less than the power load, the grid supplies power shortage resulted by inverter to the load. The test results and observations on a resistive-inductive load of 300 VAR are shown in Fig. 11.

From the test results and observations presented in Fig. 12, active power load (green signal) as a whole is supplied by the grid of 418 watts (red signal) and the inverter does not generate active power. From the test and observation, it can be seen that the inverter absorbs active power from the grid at 118 watts (blue signal).

Compensation done by the inverter to transmit reactive power at resistive-inductive load can raise the profile of voltage at the load. From the test results, it can be seen that reactive power compensation is done to raise the profile of voltage at the load and is stable at $311 \mathrm{~V}_{\text {peak. }}$ The test results of reactive power compensation of 300 meters of the service are presented in Table III.

TABLE III

COMPENSATION VOLTAGE DROP ON LOAD

\begin{tabular}{|c|c|c|c|c|c|}
\hline \multirow{2}{*}{$\begin{array}{c}\text { Cos } \\
\varphi\end{array}$} & \multicolumn{2}{|c|}{ Impedance } & \multirow{2}{*}{$\begin{array}{c}\text { Drop } \\
\text { (V) }\end{array}$} & \multirow{2}{*}{$\begin{array}{c}\text { Compensation } \\
\text { (V) }\end{array}$} & \multirow{2}{*}{$\begin{array}{c}\text { Load } R(\Omega)+ \\
\quad L(\mathbf{m H})\end{array}$} \\
\hline & $\begin{array}{c}R \\
(\Omega)\end{array}$ & $L(\mathrm{mH})$ & & & \\
\hline 0.71 & 0.29 & 0.00036 & 297.4 & 310.99 & $81.45+256$ \\
\hline 0.8 & 0.29 & 0.00036 & 298.7 & 311.08 & $103.34+245$ \\
\hline 0.85 & 0.29 & 0.00036 & 299.2 & 311.15 & $116.22+229$ \\
\hline 0.9 & 0.29 & 0.00036 & 304.8 & 311.24 & $129.74+202$ \\
\hline 0.95 & 0.29 & 0.00036 & 306.6 & 311.38 & $146.74+202$ \\
\hline
\end{tabular}

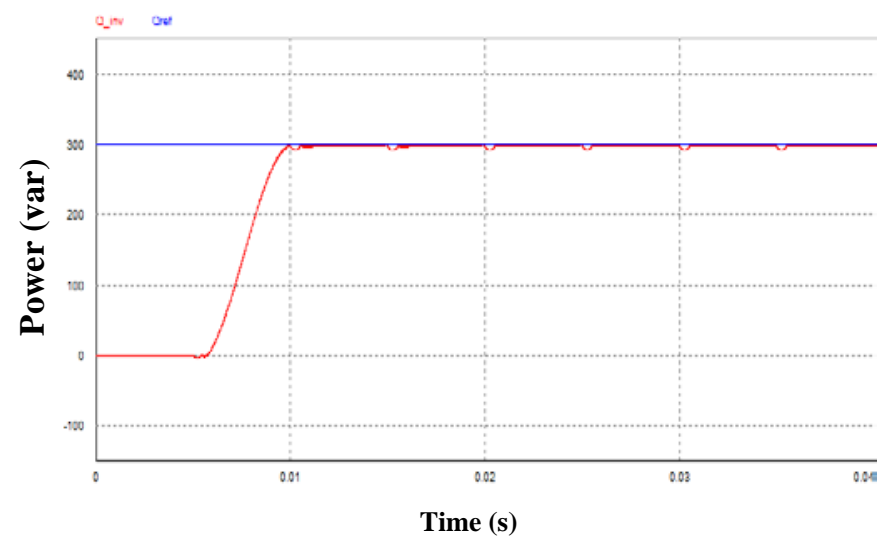

Fig. 15 Steady-state error of $0.11 \%$.

It can be seen from the test results that the voltage drop across the load occurs locally. The voltage drop on the local load before their reactive power compensation is shown in Fig. 13.

In Fig. 14, it can be seen the results of reactive power compensation of the local load by the inverter. With the reactive power compensation of the inverter, the voltage on the local load can be increased and stabilized at $310.999 \mathrm{~V}_{\text {peak }}$.

\section{Test results of Proportional Integrator Current Control}

Transformation-based PI control of dq can reduce steadystate error to zero, but in the simulation, steady state error reaches $0.11 \%$. It is obtained blue signal as a representation of the reference power and the red signal is a representation of the output of the inverter reactive power. The simulation results of PI current are presented in Fig. 15.

\section{CONCLUSION}

From the test results, the conclusions can be drawn as follows. The voltage of the local load could be successfully raised and stabilized at $219.88 \mathrm{~V}_{\text {rms }}$ after the availability of 
reactive power compensation that is provided by the inverter. The reactive power generated by the inverter is $298 \mathrm{VAR}$. The PLL can work well so that it ensures the inverter can remain synchronized with the grid. Meanwhile, the PI current control on the inverter can reduce the steady-state error to be $0.11 \%$ of the reference of power delivered without oscillation.

\section{ACKNOWLEDGMENTS}

This study could be completed because of the efforts, prayer, support, and encouragement given by all parties.

\section{REFERENCES}

[1] D. M. Scholten, N. Ertugrul, and W. L. Soong, "Micro-Inverters in Small Scale PV Systems: A Review and Future Directions," Australasian Universities Power Engineering Conference (AUPEC 2013), 2013, pp. 1-6.

[2] S. Rahayu, "Perancangan Flyback DC-DC Converter 350 Watt dengan Mode Non-Interleaved dan Interleaved Berbasis LT 3757 Menggunakan LT Spice,” Thesis, Universitas Gadjah Mada, 2017 (in Indonesian).

[3] Turahyo, "Pengembangan Inverter Satu Fase Berbasis DDS untuk Perbaikan Kualitas Tegangan Listrik pada Rumah Tangga Perkotaan Padat,” Thesis, Universitas Gadjah Mada, 2016 (in Indonesian).

[4] A. A. Salam, A. Mohamed, and M. A. Hannan, "Technical Challenges on Microgrids,” Arpnjournal, Asian Res. Publ. Netw., Vol. 3, No. 6, pp. 64-69, 2008.

[5] M. R. Patel, Wind And Solar Power Systems, Florida, USA: Crc Press, 1999.

[6] Toni, “Desain Konverter DC-DC Topologi Full-Bridge 311/100 V 1 KW dengan Metode Geser Fase PWM untuk Mendapatkan Kondisi
Zero Voltage Switching (ZVS),” Thesis, Universitas Gadjah Mada, 2016 (in Indonesian).

[7] Mohan, Power Electronics, Converters, Applications, and Design, USA: John Wiley And Sons, Inc., 1989.

[8] Muhammad H. Rashid, Power Electronics, Academic Press Series in Engineering, 2001.

[9] S. B. P. Khluabwannarat, C.Thammarat, S. Tadsuan, "An Analysis of Iron Loss Supplied by Sinusoidal, Square Wave, Bipolar PWM Inverter, and Unipolar PWM Inverter,” Int. Power Eng. Conf. (Ipec), Ieee Conf. Publ., 2007, pp. 1185-1190.

[10] L. Bowtell and T. Ahfock, "Comparison Between Unipolar and Bipolar Single Phase Grid- Connected Inverters for PV Applications," Australasian Univ. Power Eng. Conf. Ieee Conf. Publ., 2007, pp. 1-5.

[11] Marco Liserre, Remus Teodorescu, Pedro Rodriguez, Grid Converters for Photovoltaic and Wind Power Systems, John Wiley And Sons, Ltd, Publication, 2011.

[12] T. Kerekes, "Analysis and Modeling of Transformerless Photovoltaic Inverter Systems,” Ph.D. Thesis, Aalborg University Institute of Energy Technology, Denmark, 2009.

[13] B. Crowhurst, L. El Chaar, and L.A. Lamont, "Single-Phase Grid-Tie Inverter Control Using DQ Transform for Active and Reactive Load Power Compensation," IEEE Int. Conf. Power Energy, IEEE Conf. Publ., 2010, pp. 489-494.

[14] "Buku 1 Kriteria Disain Enjinering Konstruksi Jaringan Distribusi Tenaga Listrik,” PT PLN Publ., 2010 (in Indonesian).

[15] “All Aluminum Alloy Conductor (AAAC) SPLN 41-8 : 1981”, PT PLN Publ., 1981.

[16] A. Yuana and D. Rachman, "Perencanaan Saluran Udara Tegangan Menengah (SUTM) $20 \mathrm{KV}$ pada Komlek Perkebunan AMP (Agra Masang Perkasa ) Bawan Lubuk Basung,” J. Tek. Elektro ITP, Inst. Teknol. Padang Publ., Vol. 1, No. 2, 2012 (in Indonesian). 